\title{
New Stability Indicating Method for Quantification of Impurities in Amlodipine and Benazepril Capsules by Validated HPLC
}

\author{
Rama Joga Venkata Eranki ${ }^{1,2 *}$, Gopichand Inti ${ }^{1}$, Venkatasubramanian Jayaraman ${ }^{1}$, \\ Raghuram Pannala ${ }^{3}$, Sudhakar Rao Vidiyala ${ }^{1}$, Jadi Sree Ramulu ${ }^{2}$ \\ ${ }^{1}$ Quality \& Analytical Development Department, InvaGen Pharmaceuticals, Inc., Hauppauge, USA \\ ${ }^{2}$ Department of Chemistry, Sri Krishnadevaraya University, Anantapur, India \\ ${ }^{3}$ Quality Assurance Department, ScieGen Pharmaceuticals, Inc., Hauppauge, USA \\ Email: 'ramjoga@yahoo.com
}

Received October 21, 2013; revised November 25, 2013; accepted December 1, 2013

Copyright (C) 2013 Rama Joga Venkata Eranki et al. This is an open access article distributed under the Creative Commons Attribution License, which permits unrestricted use, distribution, and reproduction in any medium, provided the original work is properly cited.

\begin{abstract}
A stability indicating LC method was developed for the simultaneous determination of Amlodipine and Benazepril capsules in pharmaceutical dosage form. Efficient chromatographic separation was achieved on Symmetry $\mathrm{C}_{18}$ stationary phase with simple combination of amobile phase containing $750 \mathrm{~mL}$ of DI Water, $250 \mathrm{~mL}$ of Acetonitrile and $2 \mathrm{~mL}$ of Octylamine into suitable container with adjusted $\mathrm{pH}$ to $2.50 \pm 0.05$ with the aid of Ortho phosphoric acid delivered in an isocratic mode and quantification was carried out using UV detection at $240 \mathrm{~nm}$ at a flow rate of $1.0 \mathrm{~mL} \cdot \mathrm{min}^{-1}$ with an injection volume of $20 \mu \mathrm{l}$ and ambient column temperature. This method is capable to detect both the drug components of Amlodipine and Benazepril in presence of their degradation products (Amlodipine Imp-A and Benazepril Impurity-C) with a detection level of $0.05 \%$. Amlodipine/Benazepril in their combination drug product were exposed to thermal, photolytic, hydrolytic and oxidative stress conditions, and the samples were analysed. Peak homogeneity data of Amlodipine and Benazeprilis were obtained using PDA detector, in the stressed sample chromatograms, demonstrating the specificity. The method shows excellent linearity over a range of $0.05 \%-2.0 \%$ for Amlodipine, Amlodipine Impurity-A and $0.05 \%-5.0 \%$ for Benazepril and Benazepril Impurity-C. The correlation coefficient for Amlodipine and Benazepril is 1 . The relative standard deviation was always less than $2 \%$. The proposed method was found to be suitable and accurate for quantitative determination and the stability study of Amlodipine and Benazepril in pharmaceutical preparations. The developed HPLC method was validated with respect to linearity \& range, accuracy, precision and robustness.
\end{abstract}

Keywords: Column Liquid Chromatography; Method Validation; Stability Indicating Study Amlodipine and Benazepril

\section{Introduction}

The amlodipine besylate component of amlodipine/benazepril capsules is chemically described as 3-ethyl-5-methyl ( \pm )-2-[(2-aminoethoxy)methyl]-4-(2-chlorophenyl)-1, 4-dihydro-6-methyl-3,5-pyridinedicarboxylate, monobenzenesulphonate [1]. Amlodipine is a dihydropyridine calcium antagonist (calcium ion antagonist or slow-channel blocker) that inhibits the movement of calcium ions into vascular smooth muscle cells and cardiac muscle cells.

"Corresponding author.
Amlodipinebesylate is a white to pale yellow crystalline powder, slightly soluble in water and sparingly soluble in ethanol.

Amlodipine besylate has an empirical formula of

$\mathrm{C}_{20} \mathrm{H}_{25} \mathrm{ClN}_{2} \mathrm{O}_{5} \cdot \mathrm{C}_{6} \mathrm{H}_{6} \mathrm{O}_{3} \mathrm{~S}$, and its molecular weight is 567.1, its structural formula is shown in Scheme 1.

Benazepril, the active metabolite of benazepril, is a no sulfhydryl angiotensin-converting enzyme (ACE) inhibitor. Benazepril is converted to benazeprilat by hepatic cleavage of the ester group.

Benazepril hydrochloride is a white to off-white crys- 
<smiles>CCOCCN1C(C)=C(C(=O)O)C(c2ccccc2Cl)C(C(=O)OCCN)=C1C</smiles><smiles>O=S(=O)(O)c1ccccc1</smiles>

Scheme 1. Amlodipine besylate chemical structure.

talline powder, soluble $(>100 \mathrm{mg} / \mathrm{mL})$ in water, in ethanol, and in methanol. Benazepril hydrochloride's chemical name is 3-[[1-(ethoxycarbonyl)-3-phenyl-(1S)-propyl] amino]-2,3,4,5tetrahydro-2-oxo-1H-1-(3S)-benzazepine1 -acetic acid monohydrochloride

Benazepril Hydrochloride has an empirical formula of $\mathrm{C}_{24} \mathrm{H}_{28} \mathrm{~N}_{2} \mathrm{O}_{5} \cdot \mathrm{HCl}$, and its molecular weight is 460.96 and its structural formula is shown in Scheme 2.

Amlodipine/Benazepril Capsules Brand name is called as Lotrel [2]. Lotrel is a combination drug, containing benazepril (Lotensin) and amlodipine (Norvasc) and is used for treating high blood pressure. Benazepril is an angiotensin converting enzyme (ACE) inhibitor. ACE is an enzyme in the body that is important for the formation of angiotensin II. Angiotensin II causes constriction of the muscles surrounding arteries in the body, thereby narrowing the arteries and elevating blood pressure. ACE inhibitors such as benazepril lower blood pressure by inhibiting the formation of angiotensin II, thus relaxing the muscles and dilating the arteries. Relaxing the arteries not only lowers blood pressure, but also improves the pumping efficiency of a failing heart and improves the pumping of blood by the heart in patients with heart failure. Amlodipine belongs to a class of medications called calcium channel blockers. These medications block the transport of calcium into the smooth muscle cells lining the coronary arteries and other arteries of the body. Since calcium is important in muscle contraction, blocking calcium transport relaxes artery muscles and dilates coronary arteries and other arteries of the body. Relaxing muscles of arteries lowers blood pressure. The FDA approved Lotrel in March 1995.

Amlodipine is official in USP [3] and Benazepril is also official in USP [4] and their combination drug product also official in USP pharmacopoeia.

Lotrel is available in a variety of dosage combinations that can be adjusted to best fit your needs. The Dosage combinations are given as amlodipine besylate equivalent to $2.5 \mathrm{mg}, 5 \mathrm{mg}$ or $10 \mathrm{mg}$ of amlodipine, with $10 \mathrm{mg}$, $20 \mathrm{mg}$ or $40 \mathrm{mg}$ of benazepril hydrochloride providing for the following available combinations: $2.5 / 10 \mathrm{mg}$, 5/10 mg, 5/20 mg, 5/40 mg, 10/20 mg and 10/40 mg.

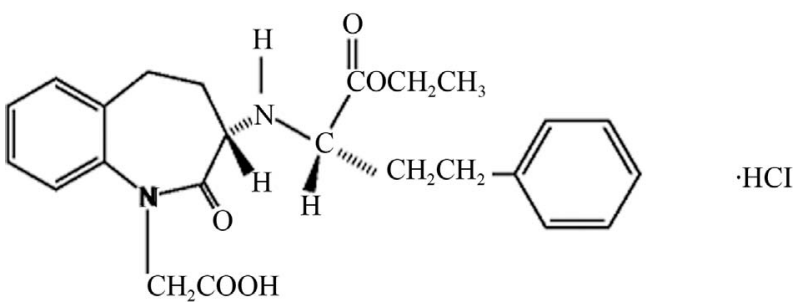

Scheme 2. Benazepril hydrochloride chemical structure.

Even though the products have been captured in USP, an in-house method has been developed and validated as per ICH guideline and monitoring of these impurities with good separation of peaks and quantification of impurities in Amlodipine/Benazepril capsules as shown in Schemes 3 and 4.

Stability testing forms an important part of the process of drug product testing to provide evidence on how quality of a drug substance or drug product varies with time under the influence of a variety of environmental factors such as temperature, humidity, light and enables recommendation of storage conditions, retest periods and shelf life to be established. The two main aspects of drug products that play an important role in shelf life determinations are assay of active drug and degradants generated during the stability study. Stability-indicating methods have been reported for assays of various drugs in drug products containing only one active drug substance. Only few stability-indicating methods are reported for the impurity assay of combination drug products containing two or more active drug substances. The objective of this work was to develop an analytical LC procedure, which would serve as stability-indicating impurity assay method for combination drug products of Amlodipine and Benazepril.

The literature survey reveals that several methods were reported for the individual estimation of Amlodipine and Benazepril. Various methods using HPLC [5-7], RPHPLC [8,9], HPTLC [10,11], LC-MS [12], LCMS/MS [13] and simultaneous UV spectrophotometric methods $[14,15]$ are reported for the estimation of Amlodipine alone or Benazepril alone or in combination with other agents [16]. In USP, the reported analytical procedures describe a method for simultaneous determination of Amlodipine and Benazepril in combined pharmaceutical dosage form in the presence of their degradants with 110 minutes as runtime.

If the reported individual methods are applied for the analysis of the capsules containing Amlodipine and Benazepril, it would require UPLC to have shorter runtime and it's not possible for all to afford the same and the method would not be rapid, less expensive, or economical, whereas the simultaneous determination of the ingredients of the Capsules would be rapid, stability indicative and also economical and can be afforded by all.

In the present study, attempts were made to develop a 
<smiles>CCOC(=O)c1c(COCCN)nc(C)c(C(=O)O)c1-c1ccccc1Cl</smiles>

Scheme 3. Amlodipine impurity-A chemical structure.<smiles>O=C(O)CN1C(=O)[C@@H](N[C@@H](CCc2ccccc2)C(=O)O)CCc2ccccc21</smiles>

Scheme 4. Benazepril impurity-C chemical structure.

rapid, economical, precise and accurate method for the simultaneous estimation of the ingredients of this combination in the presence of their degradants.

\section{Experimental}

\subsection{Chemicals \& Reagents}

Samples of amlodipine Impurity-A and the Benazepril impurity-C were synthesized and characterized at Hetero Drugs and Aarti Industries Limited, India. HPLC grade acetonitrile \& Methanol was procured from Honeywell: Burdick \& Jackson, Muskegon, MI 49442 and analytical grade Octylamine was procured from Sigma Aldrich Company, 3050 spruce Street, St. Louis, MO-63103, High purity water was generated in-house from Siemens water purification system.

The product Amlodipine Tablets in Benazepril Capsules consists of dibasic calcium phosphate, microcrystalline cellulose, crospovidone colloidal silicon dioxide, magnesium stearate lactose monohydrate, pregelatinized starch and hydrogenated vegetable oil as excipients. The combination drug product samples were provided by InvaGen Pharmaceuticals, Inc. for this work.

\subsection{Chromatographic Conditions}

The chromatographic system used was Shimadzu LC 2010 HPLC system comprised of degasser, quaternary pump, auto injector, column compartment, UV detector and the system was controlled through EZ chrome software. Symmetry $\mathrm{C}_{18},(4.6 \times 150 \mathrm{~mm}), 5$ micron or equivalent (Advance Chromatography, USA), maintained at $25^{\circ} \mathrm{C}$ using a column oven, eluted with mobile phase at the flow rate of $1.0 \mathrm{~mL} \cdot \mathrm{min}^{-1}$ with Isocratic program.

Mobile Phase: Transferred $700 \mathrm{~mL}$ of DI Water, 200 $\mathrm{mL}$ of Acetonitrile and $100 \mathrm{~mL}$ of Methanol into suitable container, Added $2.0 \mathrm{~mL}$ of Octylamine and mixed well. Adjusted the $\mathrm{pH}$ to $2.50 \pm 0.05$ using Ortho Phosphoric acid. Filtered through $0.45 \mu \mathrm{m}$ nylon membrane filter and degassed.

Measurements were made with injection volume $20 \mu \mathrm{l}$ and ultraviolet (UV) detection at $240 \mathrm{~nm}$. For standard and sample solution were prepared using the diluent nothing but Mobile phase.

For analysis of forced degradation samples, the photodiode array detector (Model No. 2998) and Empower Software was used in scan mode with a scan range of 200 - $400 \mathrm{~nm}$. The peak homogeneity was expressed in terms of peak purity and was obtained directly from the spectral analysis report using the above-mentioned software.

\subsection{Preparation of Solutions}

\section{Standard Stock Solutions:}

Standard solutions were prepared by dissolving the drugs in the diluent and diluting them to the desired concentration.

\section{Amlodipine:}

$34.7 \mathrm{mg}$ AmlodipineStandard (99.8\%) was accurately weighed, transferred into a $50 \mathrm{~mL}$ volumetric flask, and dissolved with diluent.

\section{Benazepril:}

$100.0 \mathrm{mg}$ Benazepril standard (99.7\%) was accurately weighed, transferred into a $100 \mathrm{~mL}$ volumetric flask, and dissolved with diluent.

\section{Low Level Standard Preparation:}

Transferred $1.0 \mathrm{~mL}$ of each above solution in $200 \mathrm{~mL}$ flask and diluted with diluent. The concentration of Low levelstandard Preparation contains $0.0003472 \mathrm{mg} / \mathrm{mL}$ of Amlodipine Besylate and $0.00050 \mathrm{mg} / \mathrm{mL}$ of Benazepril.

\section{Detectability Level Standard Preparation:}

Transferred $5.0 \mathrm{~mL}$ of the above Low level standard solution in $50 \mathrm{~mL}$ flask and diluted with diluent. The concentration of Detectability level standard Preparation contains $0.000347 \mathrm{mg} / \mathrm{mL}$ of Amlodipine Besylate and $0.00050 \mathrm{mg} / \mathrm{mL}$ of Benazepril.

\section{Preparation of Sample:}

Weighed 20 capsules and recorded the weight. Emptied the capsules and cleaned the capsule shell with cotton swabs. Weighed the empty capsules and recorded the weight. Determined the average fill weight by subtracting empty capsule weight from filled capsule weight obtained. 
A quantity of powder equivalent to $50.0 \mathrm{mg}$ of Amlodipine was transferred into a $100 \mathrm{~mL}$ volumetric flask. To this flask, $75 \mathrm{~mL}$ of diluent were added, and the solution was sonicated for about 15 minutes with intermittent shaking and with mechanical shaking for about 15 minutes. The solution was cooled to ambient temperature. Then the volume was made up with diluent and centrifuged for about 15 minutes. Then the solution was used for injection.

\subsection{Optimization of the Chromatographic Conditions}

To develop the stability-indicating method different stationary phases like $\mathrm{C} 18$, Discovery HS C18, different mobile phases containing buffers like tri ethylamine in water, Tetra butyl ammonium hydrogen sulfate with different $\mathrm{pH}(3-5)$ and organic modifier (acetonitrile) were used.

Our objective of the chromatographic method development was to achieve a peak tailing factor $<2$, Signal to Noise Ratio should be above 10, Theoretical plates should be above 1000 for Amlodipine and Benazepril and \% RSD for 5 consecutive injection should be less than NMT $10.0 \%$ and very good separation between amlodipine Impurity-A, Benazepril Impurity-C along with drug peak amlodipine and benazepril. As this method is used for quantifying impurities in drug product only degradation products are monitored. This method is capable of separating other process related impurities also but validation was done for only degradation products at this time.

The chromatographic separation was achieved using a Symmetry $\mathrm{C}_{18},(4.6 \times 150 \mathrm{~mm}), 5$ micron or equivalent. Changing the composition of mobile phase optimized the chromatographic method. Segregation of both peaks (Amlodipine and Benazepril) was observed on any $\mathrm{C}_{18}$ or $\mathrm{CN}$ column but it was difficult to separate both drug degradants on these columns (amlodipine Impurity-A and Benazepril Impurity-C). The Symmetry $\mathrm{C}_{18}$ column showed better performance as compared to other columns.

\section{Analytical Method Validation}

The developed chromatographic method was validated for selectivity, linearity, range, precision, accuracy, sensitivity, robustness and system suitability.

\subsection{Selectivity/Specificity}

Selectivity of the developed method was assessed by performing forced degradation studies [9-13]. According to ICH [14] stress testing of the drug substance can help the intrinsic stability of the molecule and validate the stability indicating power of the analytical procedure used. Photo stability testing should be an integral part of stress testing. The standard conditions for photo stability testing are described in ICH Q1B [11]. The specificity of the developed LC method for Amlodipine and Benazepril was determined in the presence of its related compounds Amlodipine impurity-A, Benazepril impurity-C.

The stress conditions employed on Amlodipine and Benazepril capsules as degradation study includes acid hydrolysis $(5 \mathrm{~mL}$ of Conc. $\mathrm{HCl})$, base hydrolysis $(2 \mathrm{~mL}$ of $2 \mathrm{~N} \mathrm{NaOH}$ ), oxidation ( $2 \mathrm{~mL}$ of $3 \% \mathrm{H}_{2} \mathrm{O}_{2}$ ), photolysis (ICH Q1B) and thermal $\left(80^{\circ} \mathrm{C}\right)$ study.

As such sample provided the Total Impurities level as below reporting limit (BRL) which includes Amlodipine Impurity-A and Benazepril Impurity-C as BRL whereas in acid degration the sample subjected to $5 \mathrm{~mL}$ of Conc. $\mathrm{HCl}$ for 2 hours and the Total degraded impurities were found $14.85 \%$.

In Base degradation the sample subjected to $2 \mathrm{~mL}$ of $2 \mathrm{~N} \mathrm{NaOH}$ for 2 hours which produces the total impurities of $0.29 \%$ and the samples under Oxidation with $2 \mathrm{~mL}$ of $3 \% \mathrm{H}_{2} \mathrm{O}_{2}$ provides the Total impurities result as BRL.

Under UV treatment of Sample on 3 days provides the Total impurities as $0.05 \%$ and in Thermal condition at $80^{\circ} \mathrm{C}$ the total impurities were found $0.10 \%$.

For all the above, degradation studies results were presented in Tables 1(a) and (b) and related chromatograms were represented in Figures 1 through 6.

Tables 1(a) and (b) result of analysis of forced degradation study samples using the proposed method, indicating percentage of degradation and peak purity of Amlodipine and Benazepril capsules. Figure 7 refers to Related compound and Assay chromatogram of the combination drug product. Figures 8 and $\mathbf{9}$ refer to peak purity plot of Amlodipine and Benazepril respectively.

\subsection{Results and Discussion}

From the development studies, it was determined that using mobile phase as $750 \mathrm{~mL}$ of DI Water, $250 \mathrm{~mL}$ of Acetonitrile and $2 \mathrm{~mL}$ of Octylamine into a suitable container adjusted the $\mathrm{pH}$ of the solution to $2.50 \pm 0.05$ with the aid of Ortho phosphoric acid with Isocratic flow rate of $1.0 \mathrm{~mL} / \mathrm{min}$ and ambient temperature. The analytes of this combination had adequate retentions, peak shape, less tailing, more resolution between drug and it's degradantsand the chromatographic analysis time was about 60 minutes. In optimized conditions Amlodipine, Benazepril and their degradants were well separated. Typical retention times of Amlodipine and Benazepril were about 12.58 and $7.52 \mathrm{~min}$ and for amlodipine Impurity-A, Benazepril Impurity-C and benzene sulphonic acid were about $5.14 \mathrm{~min}, 3.57 \mathrm{~min}$ and $6.25 \mathrm{~min}$ respectively.

The retention time asper USP monograph method was about 110 minutes but as per in-house validated method the retention time was 60 minutes which is reduced to 
Table 1. (a) Summary on forced degradation results-percentage of degradation; (b) Summary on forced degradation results-peak purity.

(a)

\begin{tabular}{|c|c|c|c|c|c|}
\hline Stress condition & Time & $\begin{array}{c}\text { Amlodipine Imp-A } \\
\text { (\%) }\end{array}$ & $\begin{array}{c}\text { Benazepril Imp-C } \\
\text { (\%) }\end{array}$ & $\begin{array}{l}\text { Maximum individual } \\
\text { unknown impurity (\%) }\end{array}$ & Total impurities (\%) \\
\hline As such sample & 0 hour & BRL & BRL & BRL & BRL \\
\hline Conc. HCl (5 mL) & 2 hours & 7.87 & 3.19 & 3.37 & 14.85 \\
\hline 2N NaOH (2 mL) & 2 hours & BRL & 0.29 & BRL & 0.29 \\
\hline $3 \% \mathrm{H}_{2} \mathrm{O}_{2}(2 \mathrm{~mL})$ & 2 hours & BRL & BRL & BRL & BRL \\
\hline UV light & 3 days & BRL & BRL & 0.05 & 0.05 \\
\hline Thermal condition at $80^{\circ} \mathrm{C}$ & 7 days & BRL & BRL & $0.05 \mathrm{BRL}$ & 0.10 \\
\hline
\end{tabular}

\begin{tabular}{|c|c|c|c|c|c|c|c|c|}
\hline Stress condition & Time & Peak & $\begin{array}{c}\text { Peak } \\
\text { area }\end{array}$ & $\begin{array}{l}\text { Retention } \\
\text { time (min) }\end{array}$ & $\begin{array}{c}\text { Purity } \\
\text { angle }\end{array}$ & $\begin{array}{c}\text { Purity } \\
\text { threshold }\end{array}$ & Match angle & $\begin{array}{c}\text { Match } \\
\text { threshold }\end{array}$ \\
\hline \multirow{2}{*}{ Conc. HCl (5 mL) } & \multirow{2}{*}{2 hours } & Amlodipine & 203802 & 11.66 & 0.707 & 1.499 & 0.498 & 2.145 \\
\hline & & Benazepril & 448906 & 7.62 & 0.125 & 0.440 & 0.124 & 1.226 \\
\hline \multirow{2}{*}{ 2N NaOH (2 mL) } & \multirow{2}{*}{2 hours } & Amlodipine & 232198 & 11.56 & 0.413 & 0.683 & 0.605 & 1.846 \\
\hline & & Benazepril & 464553 & 7.64 & 0.090 & 0.272 & 0.128 & 1.157 \\
\hline \multirow{2}{*}{$3 \% \mathrm{H}_{2} \mathrm{O}_{2}(2 \mathrm{~mL})$} & \multirow{2}{*}{2 hours } & Amlodipine & 232336 & 11.51 & 1.013 & 1.863 & 1.136 & 2.664 \\
\hline & & Benazepril & 466682 & 7.65 & 0.178 & 0.514 & 0.158 & 1.234 \\
\hline \multirow{2}{*}{ UV light } & \multirow{2}{*}{3 days } & Amlodipine & 231330 & 11.49 & 0.415 & 0.680 & 0.685 & 1.851 \\
\hline & & Benazepril & 467746 & 7.66 & 0.090 & 0.277 & 0.117 & 1.158 \\
\hline \multirow{2}{*}{ Thermal condition at $80^{\circ} \mathrm{C}$} & \multirow{2}{*}{7 days } & Amlodipine & 233186 & 11.48 & 0.706 & 1.138 & 0.772 & 1.968 \\
\hline & & Benazepril & 467911 & 7.66 & 0.133 & 0.387 & 0.126 & 1.186 \\
\hline
\end{tabular}

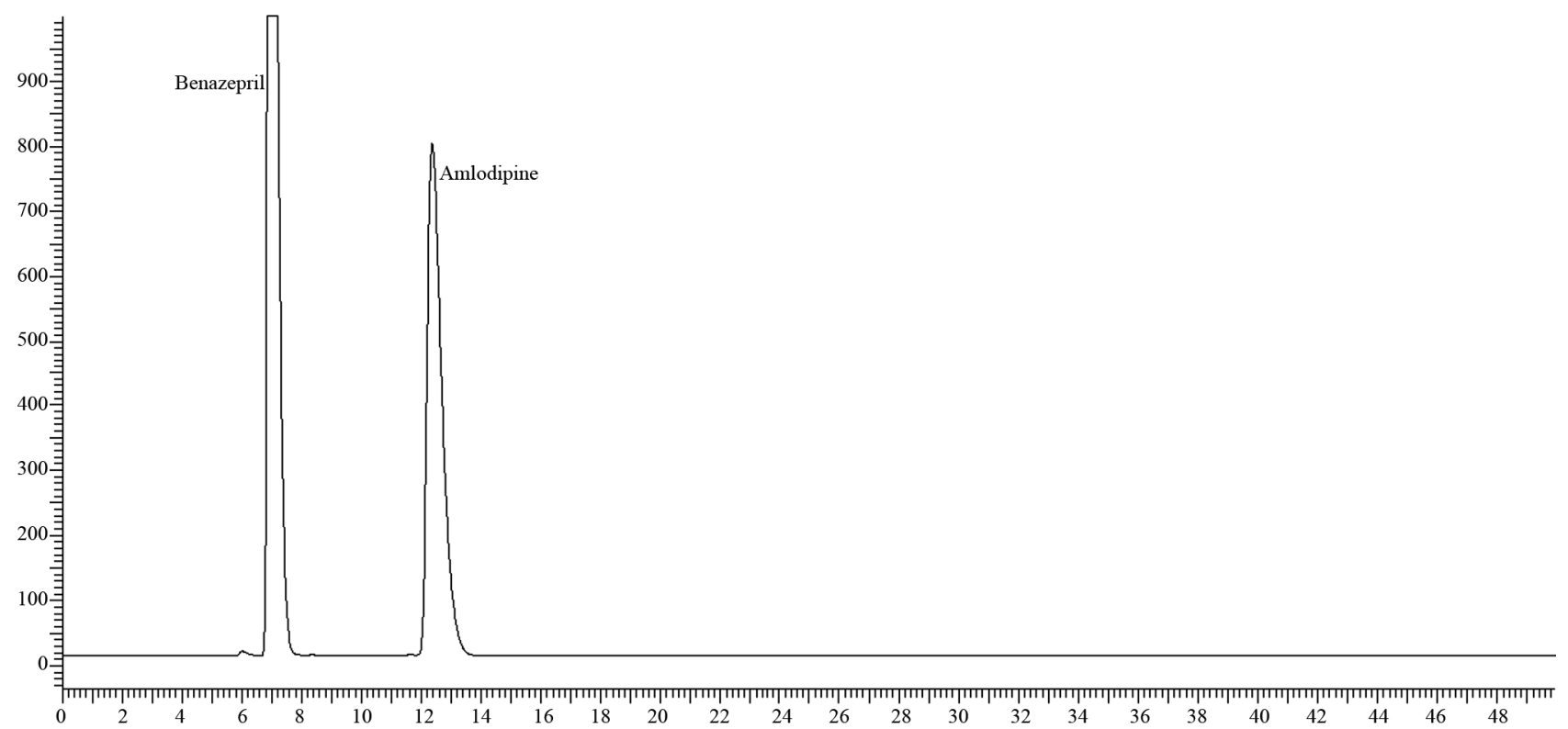

Figure 1. Chromatogram of $10 / 40 \mathrm{mg}$ sample on as such.

fifty percent of total run time and at the same time the separations were achieved to greater extent and the methods proved to be stability indicating. No EP methods are available on this combination. Instead of regular HPLC if we use UFLC the retention time can be reduced to an- other 20 minutes with the same suitability parameters. Development on UFLC is not an option in the present study keeping in view this application for cost effective generic products to help the people with low cost medicines. 


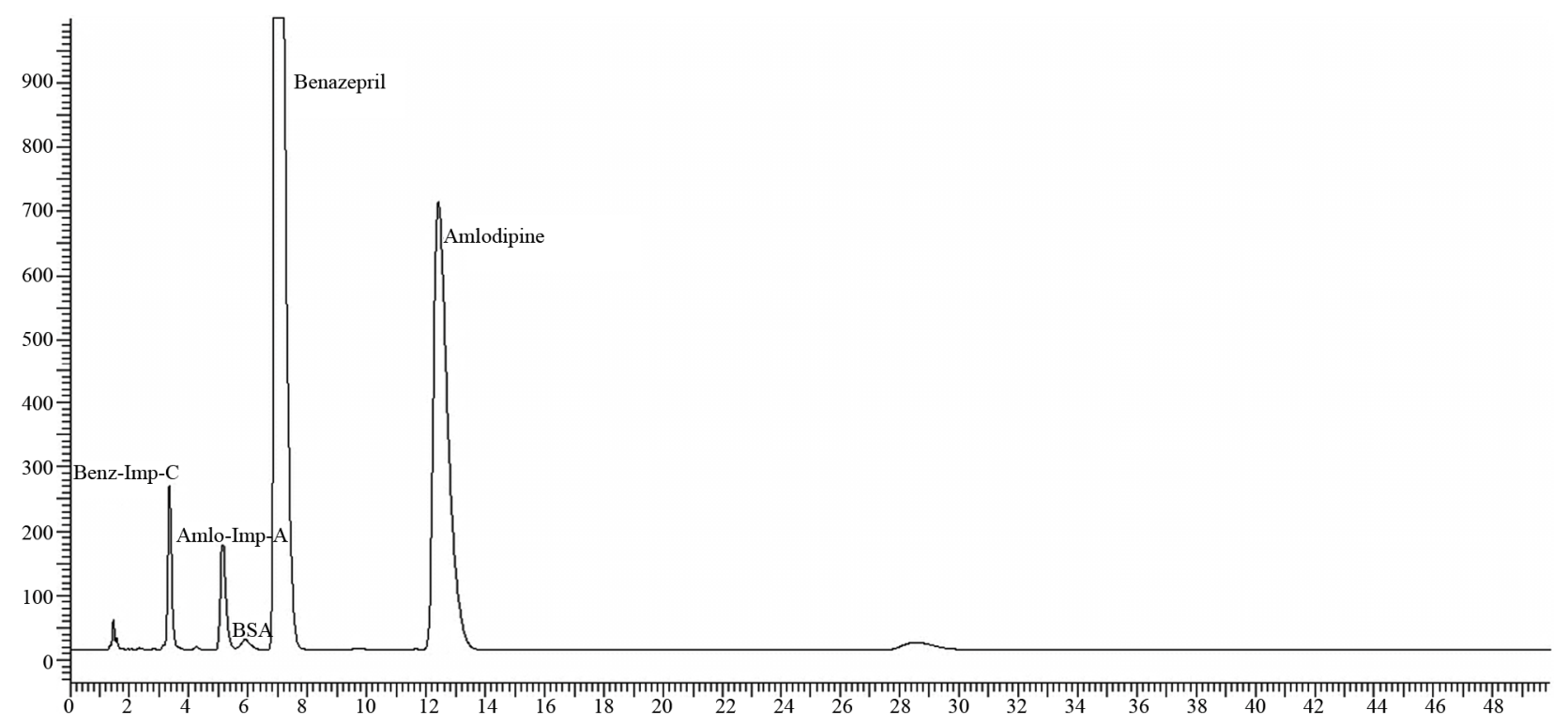

Figure 2. Chromatogram of $\mathbf{1 0 / 4 0} \mathrm{mg}$ sample on acid degradation.

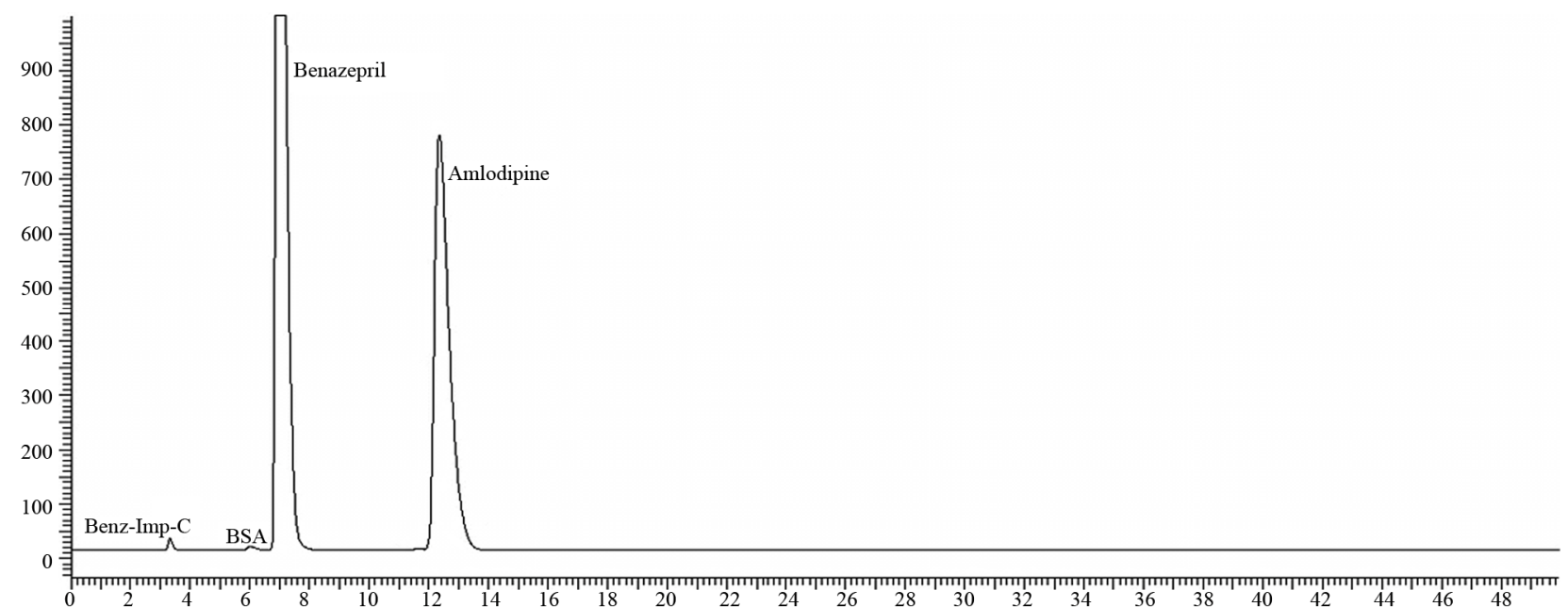

Figure 3. Chromatogram of $10 / 40 \mathrm{mg}$ sample on Base degradation.

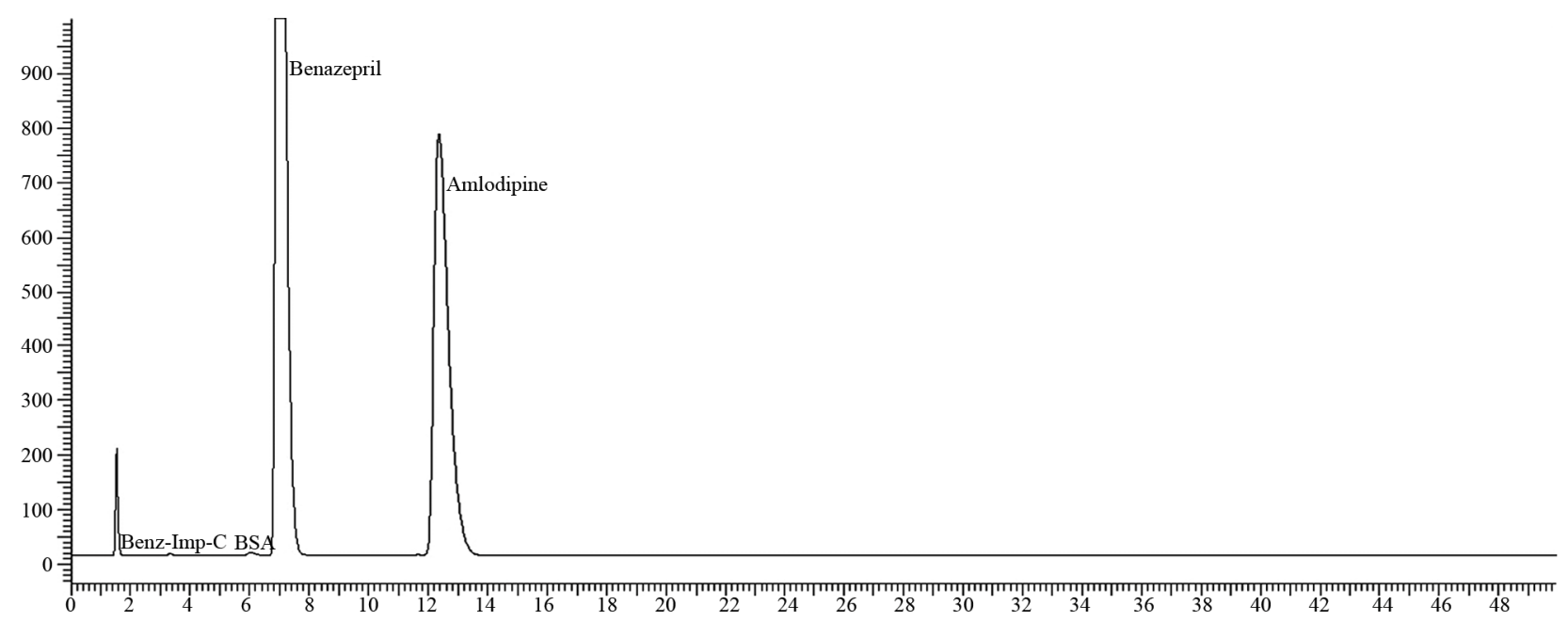

Figure 4. Chromatogram of $10 / 40 \mathrm{mg}$ sample on oxidation degradation. 


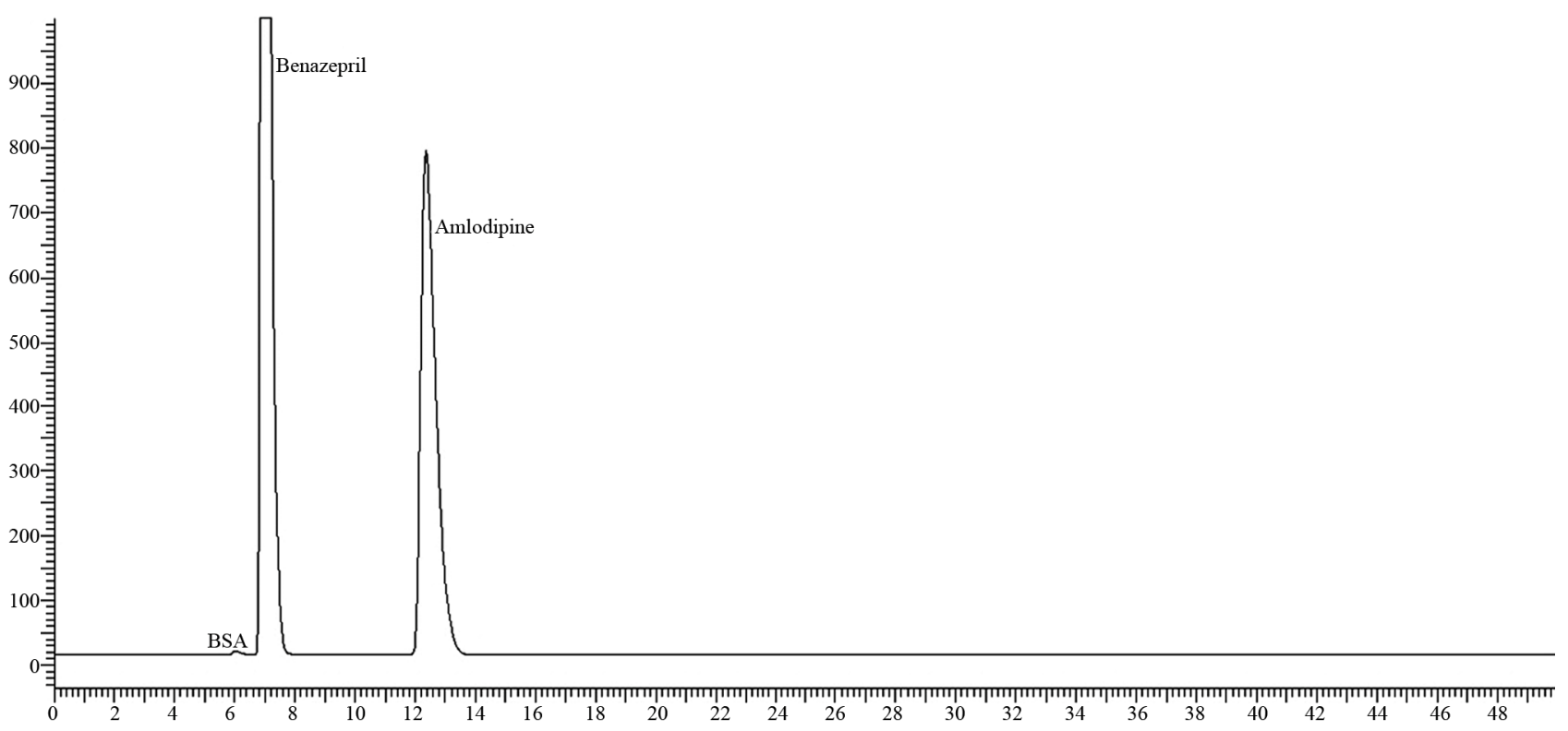

Figure 5. Chromatogram of $\mathbf{1 0 / 4 0} \mathrm{mg}$ sample on UV treatment.

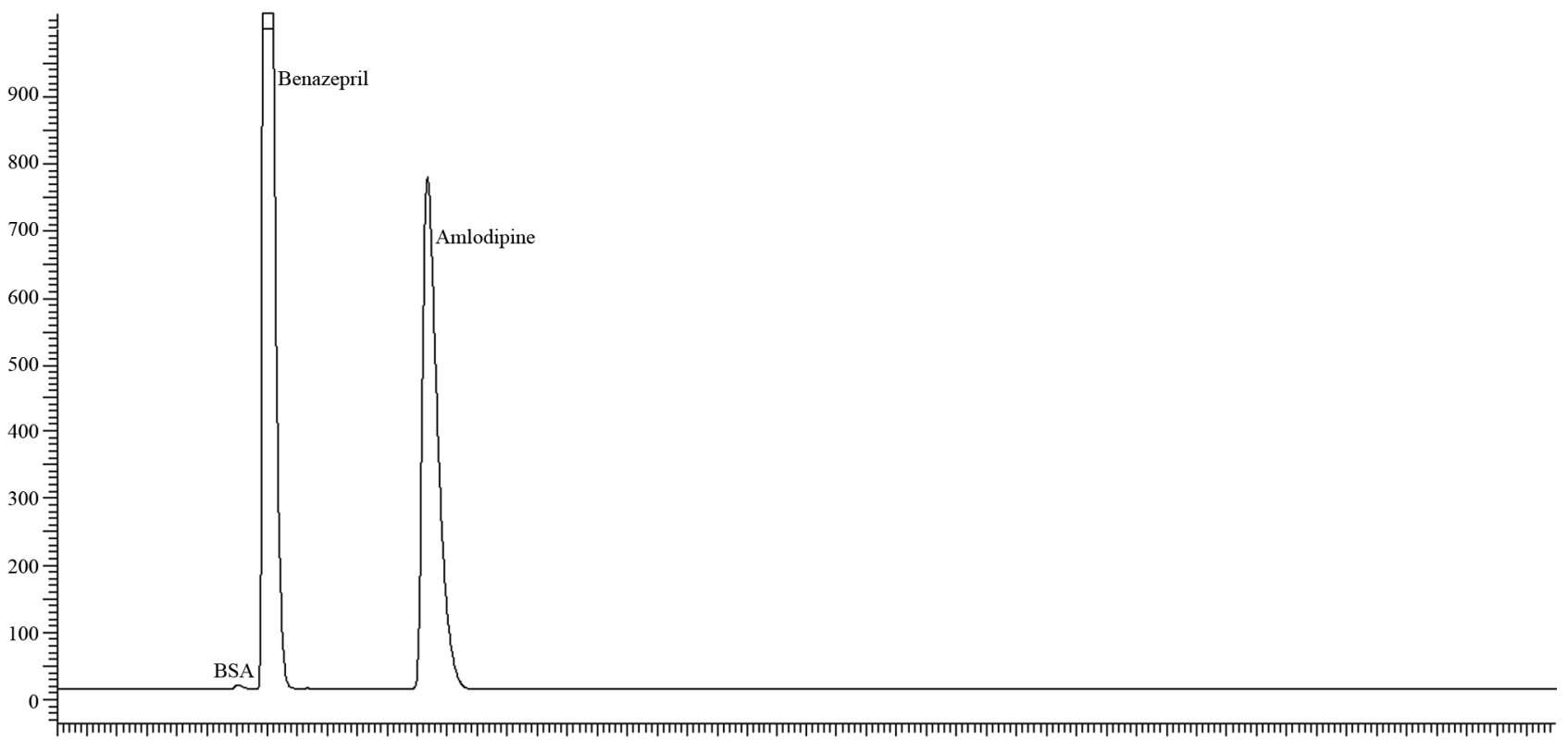

Figure 6. Chromatogram of 10/40 mg sample on Thermal treatment.

During the initial forced degradation experiments, it was observed that acid hydrolysis was a fast reaction for Amlodipine and Benazepril capsules and almost complete degradation occurred when $5 \mathrm{~mL}$ of Conc. $\mathrm{HCl}$ solution was used.Both drugs showed extensive degradation in acidic condition and indicating homogeneous peaks and thus establishing the specificity of the Impurity assay method.

\subsection{Calibration and Linearity}

Calibration curve obtained by the least square regression analysis between average peak area and concentration showed linear relationship with a regression coefficient of 0.999 over the calibration ranges tested.

The results of linearity and range obtained for the two potential impurities were tabulated. Linear calibration plot for this chromatographic method was obtained over the calibration ranges tested, i.e. $0.05 \%$ to $1.0 \%$ for Amlodipine impurity-A and $0.05 \%$ to $5.0 \%$ for Benazepril impurity-C. The correlation coefficient obtained was greater than 0.999 for the two impurities and the major compounds Amlodipine and Benazepril (Figures 10 and 11). The method exhibited good linearity with correlation coefficient values greater than 0.999 . 


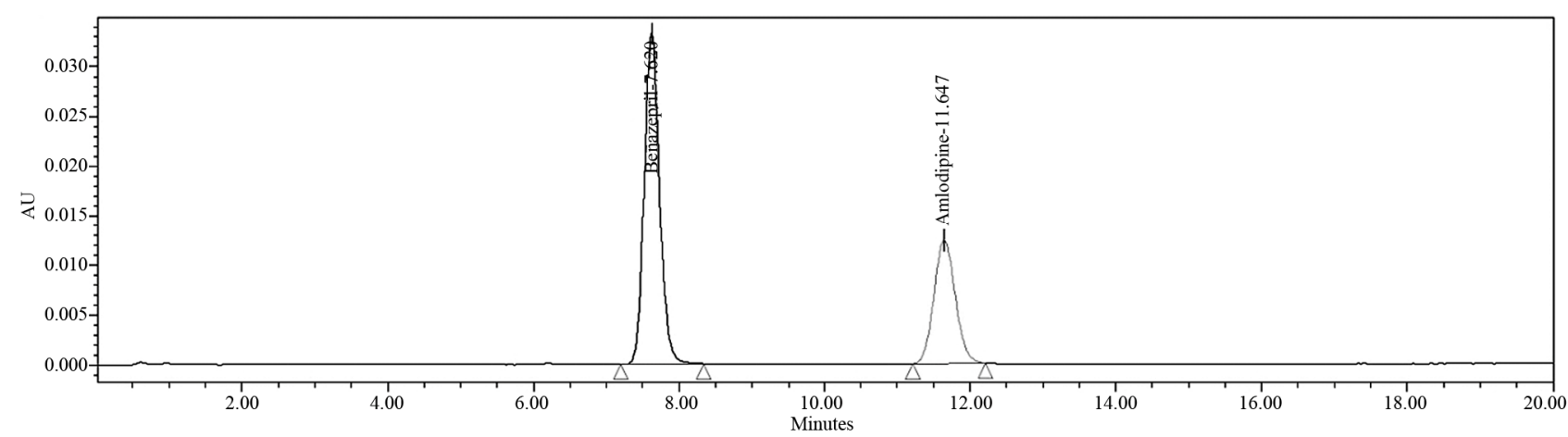

Figure 7. Related substances and Assay chromatogram of amlodipine \& benazepril 10/40 mg capsules.

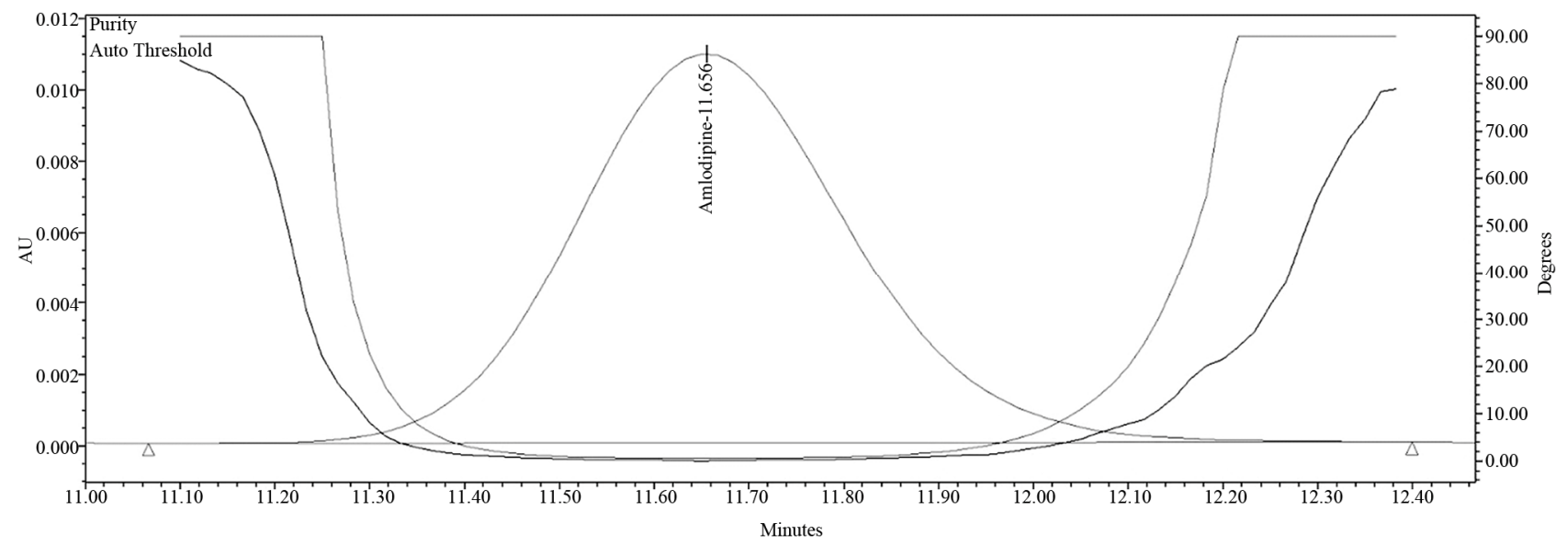

Figure 8. Purity plot of amlodipine from amlodipine \& benazepril 10/40 mg capsules.

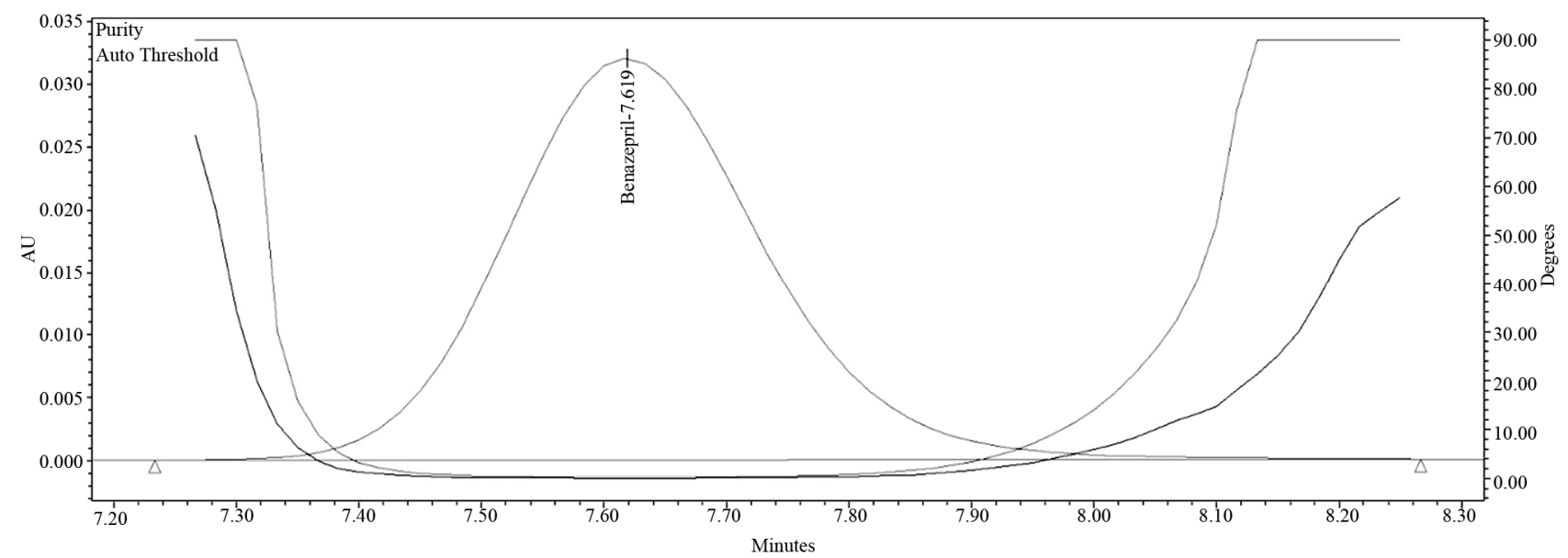

Figure 9. Purity plot of benazepril from amlodipine \& benazepril 10/40 mg capsules.

\subsection{Precision (Repeatability)}

The precision of the method was studied by determining the concentrations of each0.13 and 0.16 . The results of the precision study indicate that the method is reliable (RSD\% < 10), in Tables 2(a) and (b).

Table 2(a): \% RSD of six (6) replicate injections of each impurity should be less than 10.0, theoretical plates should be NLT 1000 and tailing factor should be NMT
2.0 for system precision.

Table 2(b): \% RSD of six (6) sample preparations for each impurity should be less than 10.0 for method precision.

\subsection{Accuracy (Recovery Test)}

The percentage recovery was established for all the analytes throughout the range concentration as explained 


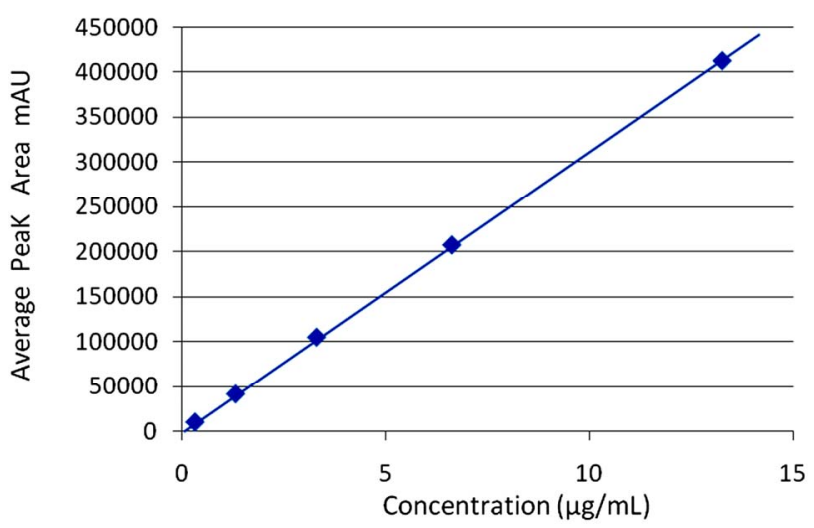

Amlodipine Impurity-A

Slope $(\mathrm{m})=31102.932$, Intercept $(\mathrm{c})=883.342$, Correlation Co-efficient $(\mathrm{r})$ $=0.9999869$.

Figure 10. Linearity for amlodipine impurity-A.

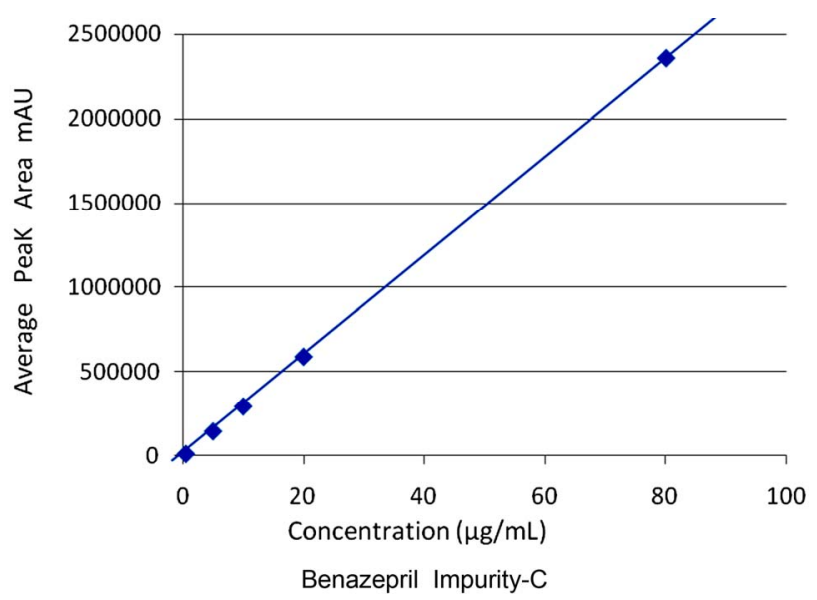

Slope $(\mathrm{m})=29317.229$, Intercept $=3378.680$, Correlation Co-efficient $(\mathrm{r})=$ 0.99999 .

Figure 11. Linearity for benazepril impurity-C.

Table 2. (a) System precision; (b) Method precision 10/40 mg.

(a)

\begin{tabular}{ccc}
\hline & Amlodipine & Benazepril \\
\hline \% RSD & 0.13 & 0.16 \\
Theoretical plates (N) & 6881.82 & 6142.15 \\
Tailing factor (T) & 1.074 & 1.094 \\
\hline
\end{tabular}

(b)

\begin{tabular}{llll}
\hline \multicolumn{2}{c}{ Amlodipine } & \multicolumn{2}{c}{ Benazepril } \\
\hline $\begin{array}{l}\text { Amlodipine } \\
\text { impurity-A }\end{array}$ & $\%$ RSD 0.0 & $\begin{array}{l}\text { Benazepril } \\
\text { impurity-C }\end{array} \quad$ \% RSD 0.0 \\
\hline
\end{tabular}

under linearity studies and obtained results are tabulated in Table 3.

\subsection{Robustness}

Robustness study was conducted by making small but
Table 3. Recovery studies results for amlodipine Imp-A and benazepril Imp-C.

\begin{tabular}{ccccc}
\hline $\mathrm{R}$ & $\begin{array}{c}\text { \% Spiking } \\
\text { level }\end{array}$ & Average peak area & \% Recovery & $\begin{array}{c}\text { Mean } \\
\text { recovery \% }\end{array}$ \\
\hline \multicolumn{5}{c}{ Amlodipine Imp-A } \\
\hline $\mathbf{0 . 4 3 0 0}$ & 0.05 & 18,083 & 121.3 & \\
$\mathbf{4 . 3 0 0 0}$ & 0.5 & 157,352 & 105.6 & 108.0 \\
$\mathbf{1 7 . 2 0 0 0}$ & 2.0 & 578,724 & 97.1 & \\
\hline \multicolumn{5}{c}{ Benazepril Imp-C } \\
\hline $\mathbf{1 . 0 0 2 0}$ & 0.05 & 14,099 & 97.4 & \\
$\mathbf{1 6 . 4 7 5}$ & 0.5 & 585,209 & 101.0 & 96.9 \\
$\mathbf{1 6 4 . 7 5}$ & 1.0 & $5,344,103$ & 92.3 & \\
\hline
\end{tabular}

deliberate changes in the optimized method parameters.

To determine robustness of the method, experimental conditions were purposely altered and chromatographic resolution between Amlodipine and Benazepril were evaluated.

The flow rate of the mobile phase was $1.0 \mathrm{~mL} \cdot \mathrm{min}^{-1}$. To study the effect of flow rate on the retention time of Amlodipine and Benazepril it was changed to $0.9 \mathrm{ml} / \mathrm{min}$ and $1.1 \mathrm{ml} / \mathrm{min}$.

The effects of $\mathrm{pH}$ variation were studied at $\mathrm{pH} 2.40$ and $\mathrm{pH} 2.60$ instead of $\mathrm{pH} 2.50$, while other mobile phase components were held constant. At all conditions the relative retention time found for Amlodipine Impurity-A and Benazepril Impurity-C were found 0.47 and 0.42 respectively. See Table 4 .

\subsection{Determination of Limit of Quantification}

Prepared Amlodipine and Benazepril LOQ solution as per the method containing the concentration of about $0.331 \mu \mathrm{g} / \mathrm{mL}$ of Amlodipine and $0.5000 \mu \mathrm{g} / \mathrm{mL}$ of Benazepril. Made five (5) replicate injections and recorded $\%$ RSD. Calculated $\mathrm{S} / \mathrm{N}$ ratio of $0.05 \%$ to establish LOQ. See Table 5.

\section{Conclusions}

The Isocratic RP-LC method developed the analysis of binary mixtures of Amlodipine and Benazeprilin. Their pharmaceutical preparation is precise, accurate and with a reasonable run time. This method is capable to detect both the drug components of Amlodipine and Benazepril in presence of their degradation products (Amlodipine Imp-A and Benazepril Impurity-C) with a detection level of $0.05 \%$.

The method was fully validated showing satisfactory data for all the method validation parameters tested. The developed method is stability-indicating, separates degradants and can be conveniently used by the quality control department to determine impurity assay of pharmaceutical preparations and also for stability sample analysis. 
Table 4. Summary on robustness parameter study.

\begin{tabular}{ccc}
\hline Parameters & Amlodipine impurity-A & Benazepril impurity-C \\
\hline Flow rate of $\mathbf{1 . 0} \mathbf{~ m L} / \mathbf{m i n u t e}$ & 0.46 & 0.43 \\
Variation in flow rate of $\mathbf{0 . 9} \mathbf{~ m L / m i n u t e}$ & 0.47 & 0.42 \\
Variation in flow rate of $\mathbf{1 . 1} \mathbf{~ m L / m i n u t e}$ & 0.47 & 0.42 \\
Variation in pH of mobile phase-2.40 & 0.47 & 0.43 \\
Variation in pH of mobile phase-2.60 & 0.47 & 0.42 \\
\hline
\end{tabular}

Table 5. S/N ratio of amlodipine, benazepril and composite impurities at LOQ $(0.05 \%)$ level.

\begin{tabular}{cccc}
\hline Component name & Concentration $\boldsymbol{\mu g} / \mathbf{m L}$ & \% RSD & Signal to noise ratio (S/N) \\
\hline Amlodipine impurity-A & 0.3310 & 0.27 & 78.915 \\
Amlodipine & 0.3469 & 0.21 & 188.860 \\
Benazepril impurity-C & 0.5010 & 0.13 & 197.081 \\
Benazepril & 0.5000 & 1.42 & 100.801 \\
\hline
\end{tabular}

\section{Acknowledgements}

The authors wish to thank the management of InvaGen Pharmaceuticals, Inc. for supporting this work. Cooperation from colleagues of Quality and Analytical Research and Development departments of InvaGen Pharmaceuticals, Inc. and Sciegen Pharmaceuticals, Inc. is appreciated.

\section{REFERENCES}

[1] S. Budavari, "The Merck Index," 14th Edition, Merck and Co. Press, Whitehouse Station, 2006.

[2] http://lotrel.org/

[3] The United States Pharmacopoeia Convention, Inc., Rockville, 2007, pp. 2466-2467.

[4] The United States Pharmacopoeia Convention, Inc., Rockville, 2007, pp. 2608-2610.

[5] A. Zarghi, S. M. Foroutan, A. Shafaati and A. Khoddam, "Validated HPLC Method for Determination of AML in Human Plasma and Its Application to Pharmacokinetic Studies," Farmaco, Vol. 60, No. 9, 2005, pp. 789-792. http://dx.doi.org/10.1016/j.farmac.2005.06.012

[6] G. Bahrami and S. H. Mirzaeei, "Simple and Rapid HPLC Method for Determination of AML in Human Serum with Fluorescence Detection and Its Use in Pharmacokinetic Studies," Journal of Pharmaceutical and Biomedical Analysis, Vol. 36, No. 1, 2004, pp. 163-168. http://dx.doi.org/10.1016/i.jpba.2004.05.016

[7] B. G. Chaudhari and N. M. Patel, "Development and Validation of HPLC Method for Simultaneous Estimation of Atorvastatin Calcium and Amlodipine Besylate," Journal of Pharmacy Research, Vol. 5, 2006, pp. 141-144.

[8] A. P. Agrekar and S. G. Powar, "Reverse Phase High Performance Liquid Chromatographic Determination of Ramipril and AML in Tablets," Journal of Pharmaceutical and Biomedical Analysis, Vol. 21, 2000, pp. 1137-1142.

[9] B. G. Chaudhari, N. M. Patel and P. B. Shah, "Stability Indicating RP-HPLC for Simultaneous Determination of Atorvastatin Calcium and AML Besylate from Their
Combination Drug Products," Chemical and Pharmaceutical Bulletin, Vol. 55, No. 2, 2007, pp. 241-246. http://dx.doi.org/10.1248/cpb.55.241

[10] K. K. Pandya, M. Satia, T. P. Gandhi, I. A. Modi, R. I. Modi and B. K. Chakravarthy, "Detection and Determination of Total AML by High Performance Thin Layer Chromatography," Journal of Chromatography B: Biomedical Sciences and Applications, Vol. 667, No. 2, 1995, pp. 315-320. http://dx.doi.org/10.1016/0378-4347(95)00016-C

[11] S. N. Meyyanthan and B. Suresh, "HPTLC Method for the Simultaneous Determination of AML and Benazepril in Their Formulations," Journal of Chromatographic Science, Vol. 43, No. 2, 2005, pp. 73-75.

http://dx.doi.org/10.1093/chromsci/43.2.73

[12] Y. Feng, L. Zhang, Z. Shen, F. Pan and Z. Zhang, "Analysis of AML in Human Plasma by Liquid Chromatography-Mass Spectrometry," Journal of Chromatographic Science, Vol. 40, 2002, pp. 49-53.

[13] J. Bhatt, S. Singh, G. Subbaiah, B. Shah, S. Kambli and S. Ameta, "A Rapid and Sensitive Liquid Chromatography Tandem Mass Spectrometry (LCMS/MS) for the Estimation of AML in Human Plasma," Biomedical Chromatography, Vol. 21, No. 2, 2007, pp. 169-175. http://dx.doi.org/10.1002/bmc.730

[14] M. D. Malesuik, S. G. Cardoso, L. Bajerski and F. A. Lanzanova, "Determination of AML in Pharmaceutical Dosage Forms by Liquid Chromatography and Ultraviolet Spectrophotometry," Journal of AOAC International, Vol. 89, 2006, pp. 359-364.

[15] R. Sahu and V. B. Patel, "Simultaneous Spectrophotometric Determination of AML Besylate and Atorvastatin Calcium in Binary Mixture," Indian Journal of Pharmaceutical Sciences, Vol. 69, No. 1, 2007, pp. 110-111. http://dx.doi.org/10.4103/0250-474X.32119

[16] V. E. Rama Joga, I. Gopichand, J. S. Venkat, V. Sudhakar and J. Sree Ramulu, "New Stability Indicating Method for Quantification of Impurities in Amlodipine and Valsartan Tablets by Validated HPLC," ISRN Medicinal Chemistry, 2013. 